\title{
The Impact of Affect on Second Language Learning: A Mixed Methods Case Study
}

\author{
Charuhasini Wathuge \\ General Sir John Kotelawala Defence University, Sri Lanka
}

\begin{abstract}
Affect includes every aspect related to feelings, emotions, moods, sensations etc. that people encounter in their lives. University students experience a rich variety of such feelings, emotions, moods and sensations in academic settings. They are also frequently subjected to emotional upheaval due to various reasons, specifically within the initial phase of their university life. Emotions experienced by students in academic settings are believed to play a major role in their academic success and achievement. However, the attention given to the role of emotions in educational settings, particularly in Second Language (L2) learning is seemingly at a low level. Therefore, the study explored the impact of academic emotions on L2 learning with a special focus on first year Undergraduate Officer Cadets studying in a defence university in Sri Lanka. This investigation took the form of a case study that subsumes a mixed methods research design. Both quantitative and qualitative methods to gather, analyse and interpret data were integrated at each stage of the study to avoid inherent biases and limitations of using only one method. Results suggested that especially during the first year, the students frequently encounter many adjustment problems due to the nature of their training, language issues and personal attributes. What appeared to be impacted mostly on real learning in this context was intrinsic motivation. Though manifestation of positive emotions inside the classroom was found to have a positive impact on students' performance, it was exposed that in educational settings where rigorous physical training is a necessity, the will power and determination gained through the experience of negative emotions seemed to assist the students to perform better in classroom activities, presentations and at exams than the impact made by the experience of positive emotions. It is therefore, recommended the university staff members to intervene in assisting the undergraduates in coping with their emotional struggles only in the right place and at the right time, as enough room should be given to the students to learn from their own affective experiences.
\end{abstract}

Keywords: Affect, L2 Learning, Classroom Emotional Climate, Undergraduates, Mixed Methods Case Study

\section{INTRODUCTION}

$\mathrm{T}$ he term affect refers essentially to the area of emotions, feelings, beliefs, moods and attitudes, which influences our behavior to a greater extent (Arnold, (2009). The affective domain as illustrated by Krathwohl, Bloom and Masia (1973) includes the manner in which individuals deal with things emotionally, where their feelings, values, appreciation, enthusiasms, motivations, attitudes etc. come into play, as such, it is differentiated from cognitive and psychomotor domains. Wetherell (2013a) identifies affect as an active agent and also argues that affect is contrasted with the discursive and the cognitive, and distinguished from 'domesticated' emotion Wetherell (2013b). Nevertheless, affect is usually used as an umbrella term to identify the different areas that frequently consider under affect (Baltazar and Saarikallio, 2016).

Positive effects of affect have long been perceived as facilitative while negative effects have been considered as imposing a negative impact on learning. For example, positive affective states or affectively positive environments have been found to put the brain in the optimal state for learning: minimal stress and maximum engagement with the material to be learned (Arnold, 2009), increase memory on various tasks given to children (Potts, Morse, Felleman, and Masters, 1986) and child compliance (Lay, Waters, and Park, 1989) whereas negative affective states or affectively negative environments have been investigated to make a lower cognitive processing effort (Leight and Ellis, 198) and produce low-effort processing of information and less use of complex semantic processing strategies in children (Ellis, Thomas and Rodriguez, 1984). Research findings of Arnold (2011) also manifest that positive affect provides invaluable support for learning while negative affect closes down the mind and prevent learning from occurring altogether. However, the findings of a study conducted by Pretz, Totz and Kaufman (2010) did not support the general conviction, that is, implicit learning would be enhanced by positive mood and intuitive cognitive style. Moreover, Méndez López and Peña Aguilar (2013) claim that students embraced negative emotions as learning opportunities because they referred to these negative events in class as a way of understanding what they were doing wrong and how to improve on that particular skill. As such, affective experiences of each individual and how they relate those experiences to them are exclusively personalised and subjective, making it further complicated to study and assess the impact of affect on individuals. Scovel (2001) also asserts that emotions might well be the factor that most influences language learning, but, is the least understood by researchers in Second Language Acquisition.

Moreover, the metaphor of the affective filter introduced by Krashen (1992) emphasizes that the emotional variables may interfere with the reception and processing of comprehensible input while learning a language, thereby, highlighting the importance of establishing a positive affective climate within the language class room. It can be claimed that affect plays a significant role in language learning and therefore, studying all 
its facets such as moods, feelings and emotions are useful in understanding the language learning processes (Swain, 2013).

This study focuses on the significant role that affect plays in any academic setting, enabling the researcher to base the investigation on feelings, emotions, moods etc. that the students typically experience during their learning. Such emotions are called academic emotions and they are those which may include enjoyment, pride, boredom, anger, hopelessness etc. - the emotions experienced in an academic setting which are related to students' learning, classroom instruction, and achievement (Pekrun, Goetz, Titz and Perry, 2002a; Pekrun, Goetz, Titz and Perry, 2002b). Students generally experience a rich variety of emotions inside the classroom, during examinations, while doing in-class activities and presentations and in many other related instances. Those emotions experienced by students in academic settings play a major role in their academic success and achievement. It is questionable whether teachers, educators, curriculum developers and policy makers think in terms of or at least are mindfully aware of the good and the bad consequences that may occur to a student due to various affective experiences they encounter within an academic setting and it is also a very challenging task to create an emotionally healthy classroom climate.

Among all the possible causes of the emotional turmoil the undergraduates undergo, language issues, specifically the change of the medium of instruction from mother tongue to a non-native language may also have created a lot of issues. In post-colonial Sri Lanka, language policy with regard to the medium of instruction was a matter of confusion and uncertainty (Balakrishnar and Thaiyamuthu, 2011). According to the medium of instruction, the existence of two types of education was inevitable; a great majority of students were taught in the vernacular schools where Sinhalese or Tamil was the medium of instruction and the rest was taught in 'English Schools' where English was the medium of instruction (Jayasuriya, 1969). Jayasuriya (1969) also claimed that later English became an inevitable tool for government employment, social mobility and prestige, thereby, creating two 'nations' within the country: one which spoke English and enjoyed the benefits of social development and the other which spoke Sinhala or Tamil and apparently lived in hopelessness. However, even after independence, the elites who controlled the key positions in the state sector continued to perpetuate English language and in parallel to that the continuing globalization made countries like Sri Lanka give 'English' a major role in academic curricula as a medium of instruction (Navaz, 2016).

Consequently, learning English as a Second Language (ESL) has become a compulsory study area within the Sri Lankan university system and knowing how to communicate appropriately in English has become a very decisive factor in academic achievement. English becoming a compulsory study area in Sri Lankan universities has a close connection with the impacts that could occur with the emergence of English as a lingua franca. There is also an increased tendency for the universities in Sri Lanka to slowly move away from vernacular education where the medium of instruction is either Sinhala or Tamil as a result of the changes that occurred over the decades in language policy and planning. Navaz (2016) also asserts that a majority of undergraduate degree programmes offered by the universities are taught in English in contrast to a very few degree programmes in Humanities and Fine Arts taught in Sinhala or Tamil. Enrollment to the English medium intakes has exponentially been expanded as a result of this tendency. Consequently, those students who have had less exposure to English and who have followed a vernacular medium of instruction during the school career may face many issues in functioning in English language when they pursue university education. Especially, the ability to comprehend lectures in academic settings has become a challenge for those students (Flowerdew and Miller, 1992). Students who have studied in a vernacular medium may not have the language proficiency to read and understand a foreign text and they may not perform well in presentations and viva voce examinations conducted in English. This situation directly affects the level of performance of the student and his/her academic success. Therefore, there is a high possibility of such undergraduates getting emotionally stressed and depressed.

Furthermore, Pancer, Hunsberger, Pratt and Alisat (2000) claim that university students are frequently subjected to emotional upheaval due to the difficulty in adjusting to the new environment. As stated before, amidst various other reasons for the difficulty in adjustment, not being well conversant with the medium of instruction, i.e., English, also apparently has a major impact. Therefore, the study is to explore the impact of academic emotions on L2 learning with a special focus on first year undergraduates in order to better assist them in the classroom to cope with negative emotions and foster positive emotions to enhance their learning.

The current study is based on the view that emotions are fundamental to learning (Hinton, Miyamoto and Della-Chiesa, 2008) and they contain useful information that are capable of guiding cognition and action (Kusche and Greenberg, 1994). "Research has shown that emotions play a significant role in the learning process and academic achievement" (Randler, Glaser-Zikuda, Vollmer and Mayring, 2011, p.359). It is true that university undergraduates undergo a lot of emotional disturbances in adjusting to the environment and it directly affects their learning in general and L2 learning in particular. Research on the impact of affect on language learning in general is prevalent as compared to the research on the impact of affect on L2 learning. Therefore, the impact of affect, particularly the impact of emotions on L2 learning in academic settings has not adequately been studied in the present university context of Sri Lanka. However, several Sri Lankan studies on anxiety have been found. For example, Hussain (2015) has investigated the factors that cause learner's language anxiety while acquiring speaking skills, 
Pereira (2015) has studied the impact of language anxiety on learner performance among undergraduates and Peiris (2017) has researched on utilizing group activities as a remedy for speaking anxiety of L2 learners. It has been observed that adequate studies on affect other than anxiety are hardly found. Hence, the present study focuses on investigating the impact of affect, specifically, the impact of academic emotions on L2 learning.

The study was carried out in a well known governmentsupported University in Sri Lanka which is an institution with a distinctive environment owing to the diversity of its student population. It has a mixture of military and civilian students from Sri Lanka and overseas. However, only the first year local Officer Cadets who are learning English as an L2, were selected as the participants of this research for three reasons; the first is due to the convenience in collecting data, the second is that their mother tongue is not English and the third is that they are subjected to various types of adjustment problems than non-military students as a result of the transition from civilian to military lifestyle. The Officer Cadets are residential students and are not allowed to visit their parents or homes unless permitted by the university which could result in a higher vulnerability of emotional disturbance during the first few months of their stay compared to the civilian students on whom such rules and regulations are not imposed. Importantly, it was claimed that first-year students are generally prone to emotional turmoil due to various reasons and many report difficulties in keeping up with their academic work (Levitz and Noel, 1989) than the senior students. As such, Officer Cadets apparently find their first year within the university challenging, though they gradually understand the need to be trained in such a manner and under such conditions that demand high emotional intelligence, since they are groomed and nurtured to become military officers in the future.

The study basically aimed at investigating how academic emotions affect L2 learning of first year Undergraduate Officer Cadets and to find out the coping mechanisms used by them to deal with negative emotions and foster positive emotions they encounter during the L2 classroom instructions, while studying and during examinations. In order to achieve the above aim, it was expected to discover what emotions Undergraduate Officer Cadets experience in academic settings: to find out precisely the emotions experienced in the English classroom; the emotions experienced while studying English and the emotions experienced during English examinations.

In addition, it was planned to identify the sources of academic emotions that affect learning and the positive and negative effects of academic emotions on L2 learning. Using the inferences made from the study, it was also expected to give recommendations on how to improve the ESL classroom to a level that a classroom climate for the learner can be created with a minimum level of emotional disturbances. The study would also provide implications for language instructors in order to better assist the students by understanding and regulating learners' emotions in fostering learner-friendly classrooms to enhance learning.

\section{METHODOLOGY}

The overall design of this study is a case study that subsumes a mixed methods research design. A case study is usually an in-depth study of an entity or an individual which is aimed at determining the variables and relationship among the variables influencing the behavior or status of the subject being investigated. The case study approach is generally rooted in the qualitative paradigm, but, according to Yin (2011), it can also be based on any mix of quantitative and qualitative evidence. To avoid the traditional criticisms of case studies, data collection and analysis of the present study have been mixed with quantitative strategies and techniques. The study is identified as a 'Triangulation' in design according to the classification of purposes of mixed methods research introduced by Greene, Caracelli, and Graham (1989) because the methods were mixed primarily to avoid the inherent biases and limitations of using only one method to assess a given phenomenon.

Affect is a very complex phenomenon that is very difficult to define, measure and understand. Therefore, understanding the role of emotions and relating its impact to human life should be done in a way to ensure that the causal links are discovered and carefully interpreted. A study rooted in a highly quantitative paradigm may fail to identify the wide array of academic emotions that the first year undergraduates experience and may fail to comprehend the impact of those emotions on L2 learning. A case study may have the potential to identify the wide array of emotions and the impact of them on L2 learning as it is based on highly qualitative evidence.

According to Eisenhardt (1989) "a case study is a research strategy which focuses on understanding the dynamics present within single settings" (p.534), and they typically combine data collection methods such as archives, interviews, questionnaires, and observations that give either qualitative or quantitative evidence or both. The present study is based on a single setting and is aimed at investigating a very dynamic phenomenon which is affect and particularly academic emotions, utilizing both quantitative and qualitative data collection tools such as questionnaire surveys and semi structured interviews.

A mixed methods approach was the best suited method for a study of this nature because the findings went beyond the commonly used correlation studies to measure emotions which largely focus on the quantitative aspect. Correlation is not devised for the analysis of causation (Wright, 1921) and it is a truism that 'you cannot infer causation from correlation' (Gardner, 1999, p.11). So, it is very difficult to prove causation from a correlational study which only employs quantitative evidence. Since the affective experiences of university undergraduates are very difficult to analyze using only the quantitative data gathered from the questionnaire 
administered, opportunity was given to the students to speak about their emotional experiences through interviews which added a lot of enriched data. As such, the results from both quantitative and qualitative paradigms were corroborated to interpret the findings. Specifically, the integration of methods for this study took place at different stages; within the research questions, within data collection, within data analysis and within interpretation.

Qualitative researchers also locate a nearby source of potential participants who are convenient in their proximity and willing to participate rather than using purposive nonrandom ways of sample selection (Robinson, 2014). This sampling strategy which is called convenient sampling was employed in the present study due to its convenience in locating potential participants.

The data collection was done according to the design of the study. Since the study encompasses a mixed methods approach, both qualitative and quantitative data collection methods were used and integrated. Mixed forms of data, including quantitative data and qualitative open-ended interview data were concurrently collected using questionnaires and semi-structured interviews.

A total of 113 students; that is, 21 students from the Faculty of Medicine (FoM), 32 students from the Faculty of Engineering (FoE) and 60 students from the Faculty of Management, Social Sciences and Humanities (FMSH) responded to the questionnaire which was approximately $40 \%$ of the first year officer cadet population of each Faculty. Out of the 113 students from the specified three Faculties who took part in answering the questionnaire, approximately $40 \%$ of the respondents from each Faculty; five students from the FoM, seven students from the FoE and 12 students from the FMSH were interviewed depending on their willingness and availability. Finally, to corroborate the findings of the study and to expand more on the findings, it was decided to interview lecturers from each Faculty who are permanent and work on a full-time basis in the university and who conducted lectures specifically for the first year undergraduates of the respective intake. Accordingly, three lecturers from each faculty were also interviewed depending on their willingness and availability.

Two separate analyses were done after conducting the study; first, the analysis of the survey data followed by the analysis of the semi structured interviews of students and lecturers. Later, qualitative and quantitative data analyses were integrated to make inferences. Since the study was largely rooted in a qualitative epistemological position and took the form of a case study, qualitative analysis was done more extensively than the quantitative analysis. The inferences were made based on the statistical results and the thematic findings of the interview data.

Since the study is based on emotions, revealing sensitive information was done carefully in a manner in which the identities of the participants are protected, for example, pseudonyms were used to record the responses of the participants. More importantly, since the study was conducted in a military setup where all research participants except most of the teacher interviewees are a part of the three forces; Army, Navy and Air Force, the researcher had to adhere to all the special ethical requirements pertaining to a military organization in all stages of the research. Before the data collection was started, the participants were briefed about the purpose of the study using their first language (Sinhala) and upon their willingness, informed consent was obtained in writing prior to their involvement. The respondents were also informed that their participation is voluntary. Moreover, anonymity of the participants and confidentiality of their responses were ensured by retaining the individual results absolutely confidential.

\section{FINDINGS}

The analyses of survey and interview data implied that the first year Undergraduate Officer Cadets encounter a variety of positive and negative emotions connected to the present moment, past incidents and future (see Table 01). Most of these emotions are felt owing to the strict military training they have to undergo while reading for their bachelor's degree which requires a lot of energy, time and hard work. As a result, especially during the first year, they frequently encounter many problems: social and academic adjustment problems, homesickness, loneliness and heavy work overload. Seemingly, institutional demands such as working according to a strict daily routine, compulsory participation in different events organized, engaging in sports and extracurricular activities, compulsory physical exercises and tests etc. have also created many stressful situations for them. Therefore, they usually experience a range of emotions, both positive and negative, within the University due to various internal and external factors. Specifically, positive emotions such as enjoyment, pride, hope and negative emotions such as shame, fear, anxiety, boredom and anger were commonly experienced by most of the respondents. However, it was claimed by the teacher interviewees that Officer Cadets were trained to work under pressure, so that almost all of them would gradually learn to endure most of the difficulties, including the affective breakdowns that could happen and they find ways to overcome them at their own phase.

Table 01 Emotins Experienced By Undergradute Officer Cadets

\begin{tabular}{|l|l|l|}
\hline & Positive Emotions & Negative Emotions \\
\hline $\begin{array}{l}\text { Connected to } \\
\text { the present }\end{array}$ & $\begin{array}{l}\text { Enjoyment } \\
\text { Enthusiasm } \\
\text { Excitement } \\
\text { Cheerfulness }\end{array}$ & $\begin{array}{l}\text { Boredom } \\
\text { Shame } \\
\text { Fear }\end{array}$ \\
\hline $\begin{array}{l}\text { Connected to } \\
\text { the past }\end{array}$ & $\begin{array}{l}\text { Satisfaction } \\
\text { Fulfillment } \\
\text { Pride } \\
\text { Relief }\end{array}$ & $\begin{array}{l}\text { Sadness } \\
\text { Disappointment } \\
\text { Frustration } \\
\text { Guilt and Shame } \\
\text { Anger }\end{array}$ \\
\hline $\begin{array}{l}\text { Connected to } \\
\text { the future }\end{array}$ & Anticipated joy & $\begin{array}{l}\text { Anxiety and Fear } \\
\text { Despair } \\
\text { Hopelessness }\end{array}$ \\
\hline
\end{tabular}




\section{A. Participants' Exposure to English}

When evaluating participants' exposure to English during the childhood, it was found that only a minority of the respondents had been exposed to English at home and schools were the major source of learning English. This finding matched with the distribution of participants according to their socio-economic status (see Table 02 ). A majority (61.9\%) of the target group were from lower middle-class families and it could be assumed that the educational and economic status of the families had exposed the students to less or no English at home, thereby, allowing them to learn English mainly from school. This situation seemingly affected the students who studied in the vernacular medium of instruction during their school career since familiarizing themselves with English as the medium of instruction within the university also burdens them with a lot of problems including language anxiety apart from the other challenges they face as a result of the new change in life. The results revealed that language anxiety negatively affected learning in general and language learning in particular within the context which confirmed the results of the investigations on language anxiety carried out by Pishghadam et al., (2016), Henter, (2014) and Siročić, (2014). This finding exhibits how affect can negatively affect on learning and using English when student transition into higher education takes place.

Table 02 Socioeconomic Status And Exposure To English

\begin{tabular}{|c|c|c|}
\hline Social Class & Percentage & Exposure to English \\
\hline Upper Class & $01.8 \%$ & Mostly at home \\
\hline $\begin{array}{c}\text { Upper Middle } \\
\text { Class }\end{array}$ & $31.9 \%$ & $\begin{array}{c}\text { Supportive environment at home } \\
\text { and learning occurred mostly in } \\
\text { school }\end{array}$ \\
\hline $\begin{array}{c}\text { Lower Middle } \\
\text { Class }\end{array}$ & $61.9 \%$ & Mostly in school \\
\hline Lower Class & $04.4 \%$ & Only in school \\
\hline Total & $100 \%$ & - \\
\hline
\end{tabular}

\section{B. Beliefs on the Ability to Use English}

The next facet that was investigated is the students' beliefs on their ability to use English. It was revealed that the results of the questionnaire and interviews of both students and lecturers on the students' beliefs on their ability to use English were congruent. According to the results, Officer Cadets were reluctant to give up learning English easily and it seemed that most of the students believed in their ability to perform a task in front of the classroom. The students' will power, determination and confidence made them strong enough to face any situation and pertaining to English language, selfefficacy beliefs were very helpful for the participants in speech activities, presentations and oral tests than in written examinations. Moreover, data gathered through student interviews showed that the lecturers' and friends' beliefs on students' ability to perform well in English in front of an audience have also helped a majority of participants to develop their self-efficacy beliefs and perform satisfactorily in in-class presentations and speech activities.

The respondents were also asked how far they think that they themselves, their family members, English lecturers, other lecturers, friends, seniors and military officers believe in their ability to use English. The respondents were given a chance to select an answer from five options: 'strongly believe', 'believe', 'cannot say', 'rarely believe' or 'never believe'. Accordingly, the questionnaire data proved that the percentage of individuals believing in their ability to use English well was higher than that of the others: family members, other lecturers, friends, senior students and military officers (see Table 03). Ultimately, it was this belief and confidence that made them satisfied, specifically in speech activities and helped them perform better at examinations. Similarly, Multon, Brown and Lent (1991) and Chemers, Hu, and Garcia (2001) have also found that self efficacy was related positively to academic performance. However, in this particular context, positive beliefs of the Officer Cadets about the ability to use English did not correlate $(r=0.035)$ with the first semester marks of English, which suggested that the cadets only believing in their abilities would not be adequate to perform better at the examinations.

Table 03 Beliefs On Using English

\begin{tabular}{|c|c|c|c|c|c|c|}
\hline Response & Self & Family & $\begin{array}{c}\text { Englis } \\
\text { h } \\
\text { Lectu } \\
\text { rers }\end{array}$ & $\begin{array}{c}\text { Other } \\
\text { Lectu } \\
\text { rers }\end{array}$ & $\begin{array}{c}\text { Frien } \\
\text { ds }\end{array}$ & $\begin{array}{c}\text { Milita } \\
\text { ry } \\
\text { Perso } \\
\text { nnel }\end{array}$ \\
\hline $\begin{array}{c}\text { Strongly } \\
\text { Believe }\end{array}$ & $12 \%$ & $16 \%$ & $05 \%$ & $05 \%$ & $07 \%$ & $07 \%$ \\
\hline Believe & $70 \%$ & $62 \%$ & $51 \%$ & $45 \%$ & $59 \%$ & $46 \%$ \\
\hline Cannot Say & $15 \%$ & $21 \%$ & $42 \%$ & $49 \%$ & $27 \%$ & $44 \%$ \\
\hline $\begin{array}{c}\text { Rarely } \\
\text { Believe }\end{array}$ & $03 \%$ & $01 \%$ & $01 \%$ & $01 \%$ & $05 \%$ & $03 \%$ \\
\hline $\begin{array}{c}\text { Never } \\
\text { Believe }\end{array}$ & $00 \%$ & $00 \%$ & $00 \%$ & $00 \%$ & $01 \%$ & $00 \%$ \\
\hline Total & $100 \%$ & $100 \%$ & $100 \%$ & $100 \%$ & $100 \%$ & $100 \%$ \\
\hline
\end{tabular}

It also seemed that the strict practices of the military staff have positively impacted on Officer Cadets to speak in English within the University. It was found that the percentage of students using English with the military officers was higher than that of the percentage of students using English with the academic staff in the University. It can be seen as a positive sign because the Officer Cadets were observed to develop their fluency in English exponentially over the years due to the constant use of English with the military officers. These findings emphasize the fact that positive affective experiences encountered in terms of efficacy beliefs of students have helped them make progress through reflection and continuous practice.

\section{The Impact of Positive and Negative Emotions}

The findings further suggested that both positive and negative emotions affected L2 learning. Similarly as Pekrun (2006) has shown, it was found that the manifestation of 
positive emotions inside the classroom had a positive impact on the performance at exams. What is striking was that in educational settings where rigorous physical training is a necessity, the will power and determination gained through the experience of negative emotions seemed to assist the students to perform better in classroom activities, presentations and at exams than the impact made by the experience of positive emotions. The interview results showed that students' memories of negative emotional experiences of failures were more powerful which impacted their effort to be successful at the next opportunity they get. These results confirm the findings of Méndez López and Peña Aguilar (2013) where they investigated that students embraced negative emotions as learning opportunities because they referred to these negative events in class as a way of understanding what they were doing wrong and how to improve on that particular skill. It was noteworthy that no one was found experiencing a feeling of giving up learning English due to the negative feelings and emotions they encountered. This attitude could have been inculcated in the students from the initial stages of their training.

It was remarkable that hope as an emotion played a major role in encouraging students to achieve good grades. Those respondents who expected that they could do well in class, who believed that studying would help them to perform better and those who believed in their capability of facing exams had achieved good grades at the first semester examination. On the whole, a majority of the participants enjoyed facing challenging exams, believed in the capability of facing exams successfully, felt proud of achieving good grades and felt relieved after facing exams. A majority of those respondents, who felt proud of their capacity to study, could achieve comparatively better results at the first semester examination.

It was also revealed that having some level of anxiety which is not harmful could help individuals to stay motivated to study and achieve good grades, whereas an excessive feeling of anxiety could hinder performance. On the whole, there was only a small minority who 'always' or 'frequently' felt anxious whereas a majority of respondents 'never' or 'rarely' felt anxious while studying. It was significant that a majority of respondents who 'never' or 'rarely' felt anxious while studying were able to achieve higher grades whereas those who felt anxious 'always' achieved lower grades. It was further found that less or no exposure to anxiety while answering the exam paper might increase the performance at the exam, because it was noted that those respondents who had less or no exposure to anxiety during exams seemingly achieved good grades.

The findings also highlighted the importance of incorporating task or activity-based learning during lectures because it was revealed that there is a difference of the intensity of the positive feelings students experience when they actively take part in an activity and successfully complete it during the lecture rather than just attending a lecture to take down notes. Moreover, there were students who said they felt sad for not completing a task successfully which implied their enthusiasm towards learning through activities. It was revealed that a majority of the participants who experienced enjoyment as an emotion while studying English and who enjoyed taking part in discussions performed better at the first semester examination. The results of the study also revealed that positive feelings related to the task served functions of directing attention towards the task, whereas positive emotions extrinsic to the task at hand distracted attention away from the task which affirmed the results of a study done by Pekrun et al. (2002a).

However, the lecturers found it difficult to motivate most of the Officer Cadets compared to the civilian students towards achieving good grades perhaps because Officer Cadets were sure about their job even if they were to pass out with a general pass. Almost all the teacher interviewees stated that Officer Cadets quite often fell asleep, usually sat in the back rows and were reluctant to volunteer to participate in activities inside the classrooms. Therefore, what appeared to impact most on real learning in this context was intrinsic motivation than extrinsic motivation. However, there was also a tendency for the Cadets to work to earn marks for the final grade. While motivation to achieve marks could have been present, it is doubtful whether real learning takes place when the students do something just for the sake of achieving marks.

Based on the results, it can be claimed that positive affective experiences had not necessarily produced solely positive effects and nor had negative affective experiences produced solely negative effects because both positive and negative affective experiences served different purposes for different students based on their individual differences and expectations. Bless and Fiedler, 1999 (as cited in Hascher, 2010) have also agreed that it is very difficult to set clear rules to prove positive emotions foster learning or that negative emotions are detrimental. Especially, in this context, it is most likely that Officer Cadets are highly motivated to learn as a result of recovering from a feeling of negativity they experience within the context. This finding depicts that affect is dynamic, subjective and the impact of various affective experiences on students would be based on how they relate those experiences to them and their environment.

\section{Sources of Emotions}

It appeared that the sources of emotions also played a significant role in manifestation of the emotions. It was identified that the days of the week, hours of the day, the mood, physical and mental health and the classroom surrounding could possibly have had an impact on the manifestation of student emotions just as Hume (2012) claimed that personality of the learner, day of the week, time of the day, weather, stress, age, sleep, exercise, social activities and gender can be generally identified as sources of emotions. Findings suggested that most of the emotions had originated in relation to the context, tasks and self. Therefore, the emotions experienced by the students in this particular 
context can be categorized into context-specific emotions, task-specific emotions and self-related emotions.

\section{E. Coping Mechanisms}

It was found that Officer Cadets used many coping mechanisms to alleviate the negative impact of emotions. The interview data showed that most of the Officer Cadets were seemingly dependent upon social support to relieve stress. They generally sought help from the peers, seniors and military officers when they encountered a problem during their first year. Especially, negative affective experiences related to the usage of L2 were usually shared with their peers though a few respondents bore these experiences themselves. It seemed mostly that the matters pertaining to the academic activities were solved within the circle of peers due to the fact that the Officer Cadets usually expect assistance to be given by the peers, Senior Officer Cadets and the military staff.

As a result, the Officer Cadets were reluctant to seek assistance from the lecturers often during their first semester. It seemed that the relationship between them and the lecturers was not that strong especially during the first semester because the Officer Cadets were closer to the military staff members. The lecturers stated that usually it takes nearly six months for the Officer Cadets to be fully familiar with the lecturers. Seemingly, they were more comfortable seeking help from the Senior Officer Cadets and the Officer In-charge of the particular intake. Nevertheless, the major source of help for them was peer support. This affirms the findings of a study done by Julia and Veni (2012) where the researchers discovered that friends within the campus were found to be the main source of support in terms of adjusting to university life. Student interviews provided enough evidence to say that peer support among the batch mates was a behaviour which was commonly seen among Officer Cadets. The lecturers also have identified the strong bond and positive helping behaviour among the Officer Cadets. The helping behaviour among the batch mates seemed to have impacted positively on them whereas falling asleep, less participation and the negative effects of groupism may have had a negative effect on their performance.

Apart from social support, all respondents disclosed that they very often used internet as a source of support for their academic activities. All of them acknowledged that internet was very useful in solving their issues pertaining to the use of English language in different situations within the University. A substantial majority of respondents also stated that their fellow Officer Cadets were a source of encouragement whenever they got stuck while doing a presentation in front of the class. Further, going home for a vacation and participation in sports activities and various events and in physical training also assisted them to alleviate the negative impacts of emotional experiences.

It was investigated that especially the first year Officer Cadets are affected by the transition to higher education, depending on their psychological attributes. Accordingly, it was inevitable that individual differences; personality, regulation of feelings and emotions, endurance, flexibility, self-reliance etc. play a massive role in adjusting a new student to the university environment. Therefore, creating healthy emotional interactions between and among new students and other related parties is very much needed. However, when compared with healthy social interactions, the healthy emotion-related interactions with new students appeared to be the mostly neglected factor. The results emphasized the necessity for providing adequate emotional support and the importance of the role of classroom-based, emotion-related interactions to promote academic achievement.

\section{CONCLUSION}

The study concludes that the Undergraduate Officer Cadets undergo a wide array of emotions including both positive and negative emotions inside the university. Among them, emotions such as pride, enjoyment, hope, relief, sadness, fear, anxiety, shame, boredom have been common to most of the respondents. The emotions encountered by the Officer Cadets in this particular setting have generally been originated in relation to the context, task at hand and self with reference to any present moment, past incidents and future events. It was investigated that positive emotions have not always impacted positively and negative emotions negatively on learning for they serve different purposes for individual students. This depicts how the complex nature and role of affect work in real life situations. However, positive emotions were found to have helped learning in different ways while intense positive emotions external to the task seemingly distracted the learner. In this context, it is most likely that Officer Cadets are highly motivated to learn as a result of recovering from a feeling of negativity they experienced than from a positive feeling. Almost all the respondents apparently related the experiences of the negative emotions with positive remarks and they considered mistakes as learning opportunities. What was striking is that rather than the impact made by the positive emotions, the determination and willpower gained through the experience of negative emotions served as a powerful weapon for the Officer Cadets to survive, learn and perform inside the university.

There are many pedagogical implications that can be derived from the study on which the recommendations can be made. The implications and recommendations could be specifically useful for the lecturers, military trainers, curriculum developers and for the management of the university as well.

A major implication for the military trainers and lecturers in a defence university would be providing adequate emotional support to students and promoting healthy emotional interactions among them to support them in the socialization process because irrespective of how stern and strict the training is, new students should be emotionally supported until they are adjusted to the new environment. Especially, the 
lecturers should be made aware of the importance of the role of classroom-based, emotion-related interactions to promote academic achievement since the findings suggested that the healthy emotional interactions are neglected as compared to the social interactions. As affect helps individuals interact successfully with others quite similarly as behavior and cognition do, the key role played by affect cannot be ignored at any cost in all educational settings. The research provides implications to the lecturers' responsibility to promote highquality teacher-student relationships which impact on student learning and, more specifically, the significance of promoting a supportive classroom emotional climate which encourages both student engagement and academic achievement. Therefore, it is recommended that provision of training to lecturers, both military and civil, on how to maintain a healthy classroom emotional climate and to promote classroom-based, emotion-related interactions especially as both military and civil lecturers assist both military and civil students who are learning together in the same classroom.

In a university context where several student categories learn together and only one of the categories, Officer Cadets, is strictly trained to endure difficulties and work under pressure as a mandatory requirement for the success of their future career, intervening unnecessarily into their problems may also create bigger issues. Therefore, it is the responsibility of the lecturers and trainers to closely observe the emotional responses of the students and intervene into their problems only when it is required. That is a very challenging task because the teachers and trainers need to focus on the student as a member of a group where the characteristics of the group have to be considered as well as an individual where the individual personalities are considered.

According to the findings, what would have worked best in a context of this nature may be guiding Officer Cadets towards their goals under pressure, because learning and working under pressure is the most familiar and mostly used practice within a military context. Therefore, the trainers and teachers can exert a bearable level of pressure in guiding Officer Cadets towards their learning goals. The findings also highlighted the importance of incorporating task or activity based learning during lectures. It was revealed that students enjoyed task-based learning than attending lectures just to take down notes. This study further provides implications to the material and curriculum developers on the importance of using a relevant content-based learning approach as a strategy for getting students interested in the material. It has been found that it is likely to evoke feelings of enjoyment and reduce feelings of boredom in the students when they learn content that is relevant and valued.

Future research could embark on a similar kind of a study in the same context to identify the responses of the civilian students, the other major student category of the university, which would generate results for a comparative analysis of the impact of affect on learning of both student categories. A comparative analysis among the students of the three faculties may also be done to examine the differences of the students enrolled in the degree programmes of different disciplines and also to examine whether they have different abilities, interests and motives to learn L2.

\section{ACKNOWLEDGMENT}

I would like to extend my gratitude to Postgraduate Institute of English, The Open University of Sri Lanka for encouraging and empowering me with knowledge and experience to conduct research.

\section{REFERENCES}

[1] Arnold, J. (2009). Affect in L2 learning and teaching. Elia, 9(2009), 145-151.

[2] Krathwohl, D. R., Bloom, B. S., \& Masia, B. B. (1973). Affective Domain. McKay.

[3] Wetherell, M. (2013a). Feeling rules, atmospheres and affective practice: Some reflections on the analysis of emotional episodes. In Privilege, agency and affect (pp. 221-239). Palgrave Macmillan, London.

[4] Wetherell, M. (2013b). Affect and discourse-What's the problem? From affect as excess to affective/discursive practice. Subjectivity, 6(4), 349-368.

[5] Baltazar, M., \& Saarikallio, S. (2016). Toward a better understanding and conceptualization of affect self-regulation through music: A critical, integrative literature review. Psychology of Music, 44(6), 1500-1521.

[6] Potts, R., Morse, M., Felleman, E., \& Masters, J. C. (1986). Children's emotions and memory for affective narrative content. Motivation and Emotion, 10(1), 39-57.

[7] Lay, K. L., Waters, E., \& Park, K. A. (1989). Maternal responsiveness and child compliance: The role of mood as a mediator. Child Development, 1405-1411.

[8] Leight, K. A., \& Ellis, H. C. (1981). Emotional mood states, strategies, and state-dependency in memory. Journal of Verbal Learning and Verbal Behavior, 20(3), 251-266.

[9] Ellis, H. C., Thomas, R. L., \& Rodriguez, I. A. (1984). Emotional mood states and memory: Elaborative encoding, semantics processing, and cognitive effort. Journal of Experimental Psychology: Learning, Memory, and Cognition, 10(3), 470.

[10] Pretz, J.E., Totz, K.S., \& Kaufman, S.B. (2010). The effects of mood, cognitive style, and cognitive ability on implicit learning. Learning and Individual Differences, 20(3), pp.215-219.

[11] Méndez López, M. G., \& Peña Aguilar, A. (2013). Emotions as learning enhancers of foreign language learning motivation. Profile Issues in Teachers Professional Development, 15(1), 109124.

[12] Scovel, T. (2001). Learning new languages: A guide to second language acquisition. Boston: Heinle \& Heinle.

[13] Arnold, J., 2011. Attention to Affect in Language Learning. Online Submission, 22(1), pp.11-22. Retrieved from https://files.eric.ed.gov/fulltext/ED532410.pdf.

[14] Krashen, S., 1992. The Input Hypothesis: An Update. Linguistics and language pedagogy: The state of the art, 409-431.

[15] Swain, M. (2013). The inseparability of cognition and emotion in second language learning. Language Teaching, 46(2), 195-207.

[16] Pekrun, R., Goetz, T., Titz, W. \& Perry, R. P. (2002a). Academic emotions in students' self-regulated learning and achievement: A program of qualitative and quantitative research. Educational psychologist, 37(2), 91-105.

[17] Pekrun, R., Goetz, T., Titz, W. \& Perry, R. P. (2002b). Positive emotions in education. In E. Frydenberg (Ed.), Beyond coping: Meeting goals, visions, and challenges (pp. 149-174). Oxford, UK: Elsevier.

[18] Balakrishnar, J., \& Thaiyamuthu, T. (2011). Instruction in the English medium: A Sri Lankan case study. Retrieved from 
http://www.langdevconferences.org/publications/2011-Colombo SriLanka/13-LanguageandSocialCohesion-Chapter13.pdf.

[19] Jayasuriya, J. E. (1969). Education in Ceylon before and after Independence: 1939-1968. Associated Educational Publishers.

[20] Navaz, A.M.M. (2016). Challenges Faced by Students in English Medium Undergraduate Classes: An Experience of a Young University in Sri Lanka. Journal of Arts, Science \& Commerce. doi : 10.18843/rwjasc/v7i4(1)/19.

[21] Flowerdew, J. \& Miller, L. (1992). Student perceptions, problems and strategies in second language lecture comprehension. RELC Journal 23(2): 60-80.

[22] Pancer, S. M., Hunsberger, B., Pratt, M. W., \& Alisat, S. (2000). Cognitive complexity of expectations and adjustment to university in the first year. Journal of Adolescent Research, 15(1), 38-57.

[23] Hinton, C., Miyamoto, K., \& Della-Chiesa, B. (2008). Brain Research, Learning and Emotions: implications for education research, policy and practice 1. European Journal of education, 43(1), 87-103.

[24] Kusche, C. A., \& Greenberg, L. S. (1994). The PATHS curriculum: Promoting alternative thinking strategies. Seattle, WA: Developmental Research and Programs.

[25] Randler, C., Hummel, E., Glaser-Zikuda, M., Vollmer, C., Bogner, F. X., \& Mayring, P. (2011). Reliability and Validation of a Short Scale to Measure Situational Emotions in Science Education. International Journal of Environmental and Science Education, 6(4), 359-370.

[26] Hussain, S.N. (2015). An investigation of the factors that cause language anxiety in ESL/EFL learners while acquiring speaking skills. (master's thesis). Postgraduate Institute of English, The Open University of Sri Lanka, Sri Lanka.

[27] Pereira, S.S. (2015). Impact of language anxiety on learner performance among undergraduates. Proceedings of the annual research symposium, University of Colombo, Colombo, Sri Lanka.

[28] Peiris, A.E. (2017). Group activities as a remedy for speaking anxiety, The role of English and ELT in reconciliation: Proceedings of the $9^{\text {th }}$ international conference of slelta, National Institute of Education, Maharagama, Sri Lanka.

[29] Levitz, R., \& Noel, L. (1989). Connecting students to institutions: Keys to retention and success. The freshman year experience: Helping students survive and succeed in college, 6581.

[30] Yin, R. K. (2011). Applications of case study research. Sage.
[31] Greene, J. C., Caracelli, V. J., \& Graham, W. F. (1989). Toward a conceptual framework for mixed-method evaluation designs. Educational evaluation and policy analysis, 11(3), 255-274.

[32] Eisenhardt, K. M. (1989). Building theories from case study research. Academy of management review, 14(4), 532-550.

[33] Wright, S. (1921). Correlation and causation. Journal of agricultural research, 20(7), 557-585. Retrieved from https://www.ssc. wisc. edu/soc/class/soc952/Wright/Wright _Correlation \%20and\% 20 Causation.pdf.

[34] Gardner, R. C. (1999). Correlation, Causation, Motivation, and Second Language Acquisition, 10-24.

[35] Robinson, O. C. (2014). Sampling in interview-based qualitative research: A theoretical and practical guide. Qualitative Research in Psychology, 11(1), 25-41.

[36] Pishghadam, R., Zabetipour, M., \& Aminzade, A. (2016). Examining emotions in English language learning classes: A case of EFL emotions. Issues in Educational Research, 26(3), 508-527.

[37] Henter, R. (2014). Affective factors involved in learning a foreign language. Procedia-Social and Behavioral Sciences, 127, 373-378.

[38] Siročić, J. (2014). Language anxiety and willingness to communicate in young EFL learners (Doctoral dissertation).

[39] Multon, K. D., Brown, S. D., \& Lent, R. W. (1991). Relation of self efficacy beliefs to academic outcomes: A meta-analytic investigation. Journal of Counseling Psychology, 38, 30-38.

[40] Chemers, M. M., Hu, L. T., \& Garcia, B. F. (2001). Academic selfefficacy and first year college student performance and adjustment. Journal of Educational psychology, 93(1), 55.

[41] Pekrun, R. (2006). The control-value theory of achievement emotions: Assumptions, corollaries, and implications for educational research and practice. Educational psychology review, 18(4), 315-341.

[42] Julia, M., \& Veni, B. (2012). An analysis of the factors affecting students' adjustment at a university in Zimbabwe. International Education Studies, 5(6), 244.

[43] Hume, D. (2012). Emotions and moods. Organizational behavior,pp.258-297. Retrieved from https://catalogue. pearsoned. co.uk/ sample chapter/0132431564.pdf.

[44] Hascher, T., 2010. Learning and Emotion: perspectives for theory and research. European Educational Research Journal, 9(1), pp.13-28. Retrieved from http://journals.sagepub .com/doi/pdf/10.2304/eerj.2010.9.1.13. 
International Journal of Research and Innovation in Social Science (IJRISS) |Volume V, Issue VI, June 2021|ISSN 2454-6186 